\title{
Air Pollution Control-Electrostatic Precipitator
}

\author{
K.Seevakan, K. Sathiyamurthy, R. Suganya
}

\begin{abstract}
Electrostatic Precipitator is a dust collecting equipment in cement industry. Without Electrostatic Precipitator ,the dust concentration in the atmosphere becomes very high,resulting in the hazardous effect for living creatures in this world.Principle of Electrostatic Precipitator,its parts such asDischarge Electrodes, Collecting Electrodes, Rapping Devices and its working are discussed.By understanding the function of Electro static precipitator,in future, one can introduce a new dust collecting equipment with less maintanence
\end{abstract}

Keywords : Electrostatic Precipitator, Air Pollution, Corona, Discharge Electrodes, Collecting Electrodes, Rapping Devices

\section{INTRODUCTION}

Clean air, a basic part of a solid situation, is a blend of a wide range of gases. Two gases is transcendent: nitrogen, which makes up 78 percent of the volume of clean dry air and oxygen which makes up 21 percent. Argon, an inactive component represents just about 1 percent of clean dry air. Air is considered to be polluted when it contains certain substances in concentrations high enough and for durations long enough to cause harmful or undesirable effects on human health and property. [8],[ 10],[12]

Most air contaminants originate from combustion processes $\left({ }^{1}\right)$.In cement factories also billions of air pollutants emerge from combustion process. So the emission of dust particles should be controlled by pollution controlling equipments One of the equipment in controlling air pollution in cement industry is Electrostatic precipitator (ESP)

Cement can be manufactured by the following process. Lime stone and coal are crushed by the following process. Limestone and coal are crushed in a higher temperature $\left(1200^{\circ} \mathrm{c}\right)$ in the raw mill. The product formed in the raw mill is known as kiln .During this process some of the product will not be burned. It cannot be used for next process .It cannot be sent out to the atmosphere as it pollutes air. Therefore it is sent to the Electrostatic precipitator to collect dust particles. Kiln is then sent into clinker cooler for cooling. In cooling process also, some Dust arises and it is also sent to ESP for collection of particles. These dust particles are sent for reprocessing. The kiln is reduced to a temperature of $110^{\circ} \mathrm{c}-120^{\circ} \mathrm{c}$. The kiln is mixed with gypsum to form cement[19],[21],[23]

Revised Manuscript Received on July 22, 2019.

K.Seevakan, Deparment of Physics, Bharath Institute of Higher Education and Research, Tamilnadu,India. Email: kseevakan@gmail.com

K.Sathiyamurthy, Deparment of Physics, Bharath Institute of Higher Education and Research, Tamilnadu,India. Email: gksathiya0806@gmail.com

R.Suganya, Deparment of Physics, Bharath Institute of Higher Education and Research, Tamilnadu,India. Email :suganya_s_r@yahoo.com

\section{A .ELECTROSTATIC PRECIPITATOR}

Electrostatic precipitator is a commonly used(2).It has an efficiency of $99.95 \%$. The precipitator unit comprises baffles for distributing airflow discharge and collection electrodes, a dust clean out system and collection hoppers. Rows of discharge electrode wires hang between the collectionplates. Discharge electrodes and collection plates are placed alternatively. Discharge electrode wires are given a negative electric charge, whereas the collection plates are grounded and thus become positively charged. Gas distribution screens are used to provide uniform velocity for gases. [1],[3],[5]

FIG 1: Electrostatic precipitator

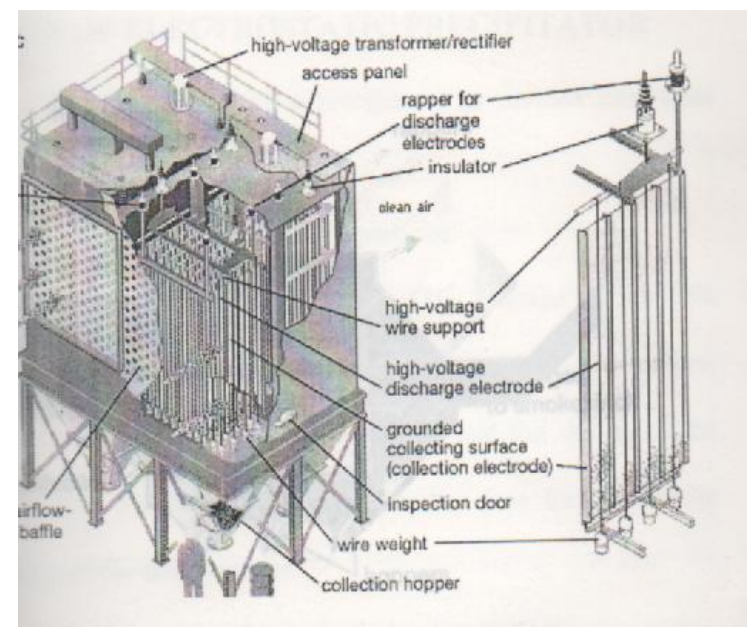

\section{PARTS OF ELECTROSTATIC PRECIPITATOR DISCHARGE ELECTRODES}

The discharge system consists of a frame of beams and tubes, the discharge electrodes being suspended within the frame work. The type and fitting method of the discharge wire is determined according to the gas condition, characteristic of dust particles and size of the electrostatic precipitator.

\section{COLLECTING ELECTRODES}

The collecting electrodes are made from $1.2 \mathrm{~mm}$ or $2.3 \mathrm{~mm}$ steel sheets with ribs to provide sufficient rigidity. They are eccentrically suspended from the precipitator roof in such a way that no destruction on thermal expansion and no strain will occur. [26],[28],[30]

\section{RAPPING DEVICES}

The rapping bars consist of two parallel flat bars linked by specially shaped intermediate pieces; one for each collecting plate.An impact anvil is mounted at the end of each 
rapping bar. This arrangement avoids a fixed connection between collecting plates and rapping bars[20],[22], [24]

\section{PRINCIPLE OF ELECTROSTATIC PRECIPITATOR}

The working principle of a precipitator is divided into three fundamental steps.

A)Electric charging of the suspended particles

A high tension rectifier impresses a D.C Voltage of $30-70 \mathrm{Kv}$ between the discharge electrodes and the collecting electrodes, depending on the nature of the process and the design of the precipitator. The discharge electrodes emit ions for the electric charging of the dust particles

B)Collection of the charged particles in an electric field

The collecting electrodes receive the precipitated dust

c) Removal of the precipitated dust from the collecting electrode[37],[39],[41]

When a certain amount of dust has accumulated on the surface of the collecting electrodes, it is made to fall down into the bottom hopper of the precipitator and is extracted.

When a high tension voltage is charged to discharge electrodes consisting of wires with a small diameter of $2-4 \mathrm{~mm}$, a certain ionization zone caused by non uniform electric field is generated around discharge electrodes. Gas molecules are separated into positive ions and negative free electrons within this ionization zone through emission of electrons. [31],[33],[35]

These ions are influenced by the strength of the electric field formed between discharge and collecting electrodes.

This electrical break down is known as"corona"which appear as a bluish glow extending into the gas a short distance beyond the surface of the discharge electrode. The generated positive ions migrate to the discharge electrodes while the negative ions migrate to the collecting electrodes. When the positive ions reach the discharge electrodes they loose their electric charge. On the other hand, the negative ions generate a certain electric wind towards the collecting electrodes through colliding with gas molecules, and thereby they loose their energy and form collecting electric field between the discharge and collecting electrodes.Therefore, if dust particles enter this field,they are ionized by negative ions.Figure explains the principle of electrostatic precipitator (4).

There are two types of mechanism in the ionization of dust particles,namely ionization by collision and ionization by diffusion.Normally particles larger than a micron diameter are ionized by collision, while smaller particles than the above are of diffusion.However,since dust collection in the practical industrial fields mainly treats particles of larger than a micron diameter,the ionization is governed by collision, of which amount is generally determined by the electric field strength within the ionization zone,the surface area of particles and charging time.

The ionized particles are drived towards the collecting electrodes by the attracting force generated proportionally to the strength of electric field.However since the velocity of the dust particle towards the collecting electrodes is affected by 'stoke's viscosity resistance;, it will eventually reach a certain equilibrium which is called as the migration velocity given by the following formula $\omega=2 \times \varepsilon 0 \times \mathrm{P} \times \mathrm{EcxEpxd} / 3 \mathrm{X} \mu$

$\varepsilon s$ : specific dielectric coefficient of dust particle

Ec: electric field strength in ionization zone

Ep: electric field strength in collecting zone

$\mathrm{d}$ : diameter of particle

$\mu$ : viscosity resistance of gas

\section{RAPPING DEVICES}

The particles migrating towards the discharge and collecting electrodes form a dust layer which is dislodged by rapping. The rapping interval for each section can be easily adjusted as required by a timer(5). Since the rapping device is directly driven by the motor from outside of the casing,the driving mechanism is so simple that maintanence work is easy dusts builds up on the collecting plates and electrodes.

1. Collecting plate build ups

With heavy dust build ups on the plates, the dust will act as an insulator and therefore high voltage is needed to get the same current.As the voltage can only be raised a little before flash over, the ESP will work with lower current and consequently with a lower efficiency.

\section{DISCHARGE ELECTRODE BUILD UPS}

Dust build ups on the discharge electrode will cause the same problem as mentioned above,but in a smaller scale[8],[ 10] ,[12] Energy reqirements and operating costs are very low. They are capable of very high efficiencies, even for very small particle.

\section{CONCLUSION}

Today, hazardous effects of trace amount of many air pollutants coming from the cement factory have been recognized and many measures have been taken to reduce pollutants. Atmosphere will be pollution free if more and more measures are taken by factories

\section{REFERENCES}

1 M., Jayaprakash P., Kumari C.R.T., Vinitha G., Caroline M.L., Growth, spectral, linear and nonlinear optical characteristics of an efficient semiorganic acentric crystal: L-valinium L-valine chloride, 2017, Physica B: Condensed Matter, V-511, PP -1-9,

2) Sangeetha P., Jayaprakash P., Nageshwari M., Rathika Thaya Kumari C., Sudha S., Prakash M., Vinitha G., Lydia Caroline M., Growth and characterization of an efficient new NLO single crystal L-phenylalanine D-methionine for frequency conversion and optoelectronic applications, 2017, Physica B: Condensed Matter, V-525, PP-164-174

3) Peer Mohamed M., Jayaprakash P., Nageshwari M., Rathika Thaya Kumari C., Sangeetha P., Sudha S., Mani G., Lydia Caroline M., Crystal growth, structural, spectral, thermal, linear and nonlinear optical characterization of a new organic nonlinear chiral compound: L-tryptophan-fumaric acid-water (1/1/1) suitable for laser frequency conversion, 2017, Journal of Molecular Structure, V-1141, PP-551-562

4) Jayaprakash P., Sangeetha P., Kumari C.R.T., Caroline M.L., Investigation on the growth, spectral, lifetime, mechanical analysis and third-order nonlinear optical studies of L-methionine admixtured D-mandelic acid single crystal: A promising material for nonlinear optical applications, 2017, Physica B: Condensed Matter, V-518, PP-1-12

5) Nageshwari M., Kumari C.R.T., Vinitha G., Mohamed M.P., Sudha S., Caroline M.L., Crystal growth, structural, spectral, thermal, dielectric, linear and nonlinear optical 
characteristics of a new organic acentric material: L-Methionine-Succinic acid (2/1), 2018, Journal of Molecular Structure, V-1155, PP-101-109

6) Jayaprakash P., Sangeetha P., Kumari C.R.T., Baskaran I., Caroline M.L., Growth and characterization of 1-asparagine monohydrate admixtured dl-mandelic acid nonlinear optical single crystal, 2017 Journal of Materials Science: Materials in Electronics, V-28, PP-18787-18794

7) Rathika Thaya Kumari C., Nageshwari M., Jayaprakash P., Sangeetha P., Sudha S., Lydia Caroline M., Investigation on growth, optical, thermal, mechanical, dielectric, LDT studies of sulphanilic acid monohydrate: A promising third-order nonlinear optical material, 2017, Journal of Nonlinear Optical Physics and Materials, V-26, I-2

8) Thaya Kumari C.R., Nageshwari M., Raman R.G., Caroline M.L., Crystal growth, spectroscopic, DFT computational and thirc harmonic generation studies of nicotinic acid, 2018, Journal of Molecular Structure, V-1163, PP-137-146

9) Nageshwari M., Kumari C.R.T., Sangeetha P., Vinitha G., Caroline M.L., Third order nonlinear optical, spectral, dielectric, laser damage threshold, and photo luminescence characteristics of an efficacious semiorganic acentric crystal: L-Ornithine monohydrochloride, 2018, Chinese Journal of Physics, V-56, I - 2, PP-502-519

10) Kumari C.R.T., Jayaprakash P., Nageshwari M., Mohamed M.P., Sangeetha P., Caroline M.L., Growth, optical, photoluminescence, dielectric, second and third order nonlinear optical studies of benzoyl valine acentric crystal, 2017, Molecular Crystals and Liquid Crystals, V-658,I - 1, PP-186-197

11) Rathika Thaya Kumari C., Nageshwari M., Sudha S., Lydia Caroline M., Mani G., Influence of uranyl on the growth, linear, laser damage threshold and nonlinear optical studies on potentia nonlinear optical single crystal: L-Alanine, 2015, Journal of Chemical and Pharmaceutical Sciences, V-2015-October,PP-166-170,

12) Rathika Thaya Kumari C., The detailed study ontwo dimensional hydrogen atom, 2013, Middle - East Journal of Scientific Research, V-17,I-12, PP-1900-1902

13) Rathika Thaya Kumari C., Theoretical study about the measurement of ultrasonic velocity using different methods, 2013, Middle - East Journal of Scientific Research, V-17, PP-12

14) Mukunthan A., Rathika Thaya Kumari C., Nageshwari M., Prakash D., The effect of super saturation and crystal growth kinetics of L-arginine per chlorate, 2013, Middle - East Journal of Scientific Research, V-17,I-12 PP-1825-1827

15) Sree Latha R., Vijayaraj R., Azhagiya Singam E.R., Chitra K., Subramanian V., 3D-QSAR and Docking Studies on the HEPT Derivatives of HIV-1 Reverse Transcriptase, 2011, Chemical Biology and Drug Design, V-78,I-12, PP-1816-1819

16) Sree Latha R., Vijayaraj R., Padmanabhan J., Azhagiya Singam E.R., Chitra K., Subramanian V., 3D-QSAR studies on the biological activity of juvenile hormone mimetic compounds for Culex pipiens Larvae, 2013, Medicinal Chemistry Research, V-22, I-12,PP-418-426

17) Subashini G.,A simple proof on coloring of dominated special graphs, Indian Journal of Science and Technology,V-7,I-,PP-5-6,Y-2014

18) Ramya N.,On coloring of corona graphs, Indian Journal of Science and Technology,V-7,I-SUPPL2,PP-9-11,Y-2014.

19) Ramya N., On colourings of wheel graph (Wn), Indian Journal of Science and Technology,V-7,I-,PP-72-73,Y-2014.

20) Ramya N., On star chromatic number of $P 3$ (n), Indian Journal of Science and Technology,V-7,I-,PP-7-8,Y-2014.

21) Vijayaragavan S.P.,An investigative expert that's general FBG sensors,International Journal of Mechanical Engineering and Technology,V-8,I-8,PP-1500-1505,Y-2017

22) Vijayaragavan S.P.,Equalization routing protocol for Wi-Fi senso strategy,International Journal of Mechanical Engineering and Technology,V-8,I-8,PP-1662-1666,Y-2017

23) Karthik B., Kiran Kumar T.V.U., Vijayaragavan P., Bharath Kumaran E.,Design of a digital PLL using 0.35 $\hat{\mathrm{I}}^{1 / 4 \mathrm{~m}}$ CMOS technology,Middle - East Journal of Scientific Research,V-18,I-12,PP-1803-1806,Y-2013

24) Kanniga E., Selvaramarathnam K., Sundararajan M.,Kandigital bike operating system,Middle - East Journal of Scientific Research,V

25) Jasmin M., Vigneshwaran T., Beulah Hemalatha S.,Design of power aware on chip embedded memory based FSM encoding in FPGA,International Journal of Applied Engineering Research,V-10,I-2,PP-4487-4496,Y-2015
26) Jasmin M.,Optimization techniques for low power VLSI circuits,Middle - East Journal of Scientific Research,V-20,I-9,PP-1082-1087,Y-2014

27) Jasmin M., Vigneswaran T.,Fuzzy controller for error control of on - Chip communication,2017 International Conference on Algorithms, Methodology, Models and Applications in Emerging Technologies, 2017,V-2017-January,I-,PP-1-5,Y-2017

28) Ramya N., On star chromatic number of P3 (n),Indian Journal of Science and Technology, V-7,I-,PP-7-8,Y-2014.

29) Cauchy Multiplication of Euler Summable series in Ultrametric Fields, PNNVS R.Deepa Commentationes Mathematicae 53 ((1)), 73- 79

30) Kumaravel A., Meetei O.N.,An application of non-uniform cellular automata for efficient cryptography,Indian Journal of Science and Technology,V-6,I-SUPPL5,PP-4560-4566,Y-2013

31) Kumaravel A., Meetei O.N.,An application of non-uniform cellular automata for efficient cryptography,2013 IEEE Conference on Information and Communication Technologies, ICT 2013,V-,I-,PP-1200-1205,Y-2013

32) Kumarave A., Rangarajan K.,Routing alogrithm over semi-regular tessellations,2013 IEEE Conference on Information and Communication Technologies,

2013,V-,I-,PP-1180-1184,Y-2013

33) Gopinath S., Sundararaj M., Elangovan S., Rathakrishnan E.,Mixing characteristics of elliptical and rectangular subsonic jets with swirling co-flow,International Journal of Turbo and Jet Engines, V-32,I-1,PP-73-83,Y-2015

34) Rathika Thaya Kumari C., A brief review on the impacts of tropospheric ozone on biological systems, 2013, Middle - East Journal of Scientific Research, V-17,I-12, PP-1820-1824

35) Mukunthan A., Rathika Thaya Kumari C., Nageshwari M., Prakash D., A brief review on the applications of fluorescent spectroscopy in biomedical diagnosis, 2013, Middle - East Journal of Scientific Research, V-17,I-12, PP-1828-1830

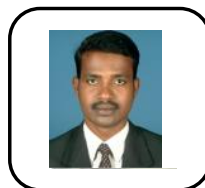

\section{AUTHORS PROFILE}

K.Seevakan Assistant Professor, Department of Physics, Bharath Institute of Higher Education and Research, Chennai, India

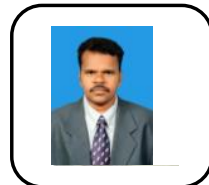

K.Sathiyamurthy Associate Professor, Department of Physics, Bharath Institute of Higher Education and Research, Chennai, India

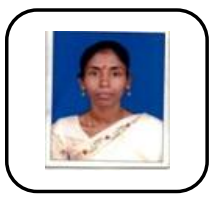

R.Suganya, Assistant Professor, Department of Physics, Bharath Institute of Higher Education and Research, Chennai, India 